\title{
Amount Recovered Infinity Predicted Normalized by Weight
}

National Cancer Institute

\section{Source}

National Cancer Institute. Amount Recovered Infinity Predicted Normalized by Weight. NCI Thesaurus. Code C112228.

The cumulative amount recovered extrapolated to infinity, calculated using the predicted value of the last non-zero concentration, divided by the weight. 